
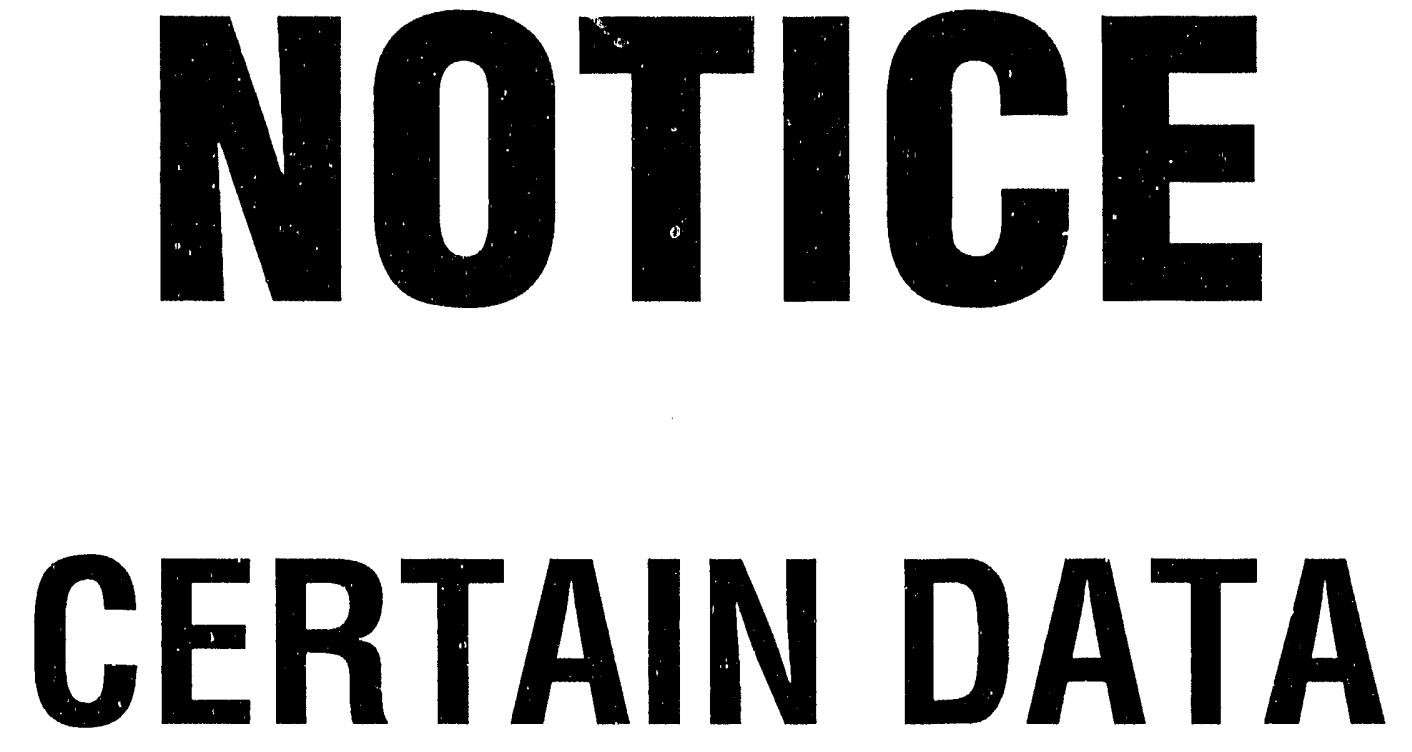

CONTAINED IN THIS
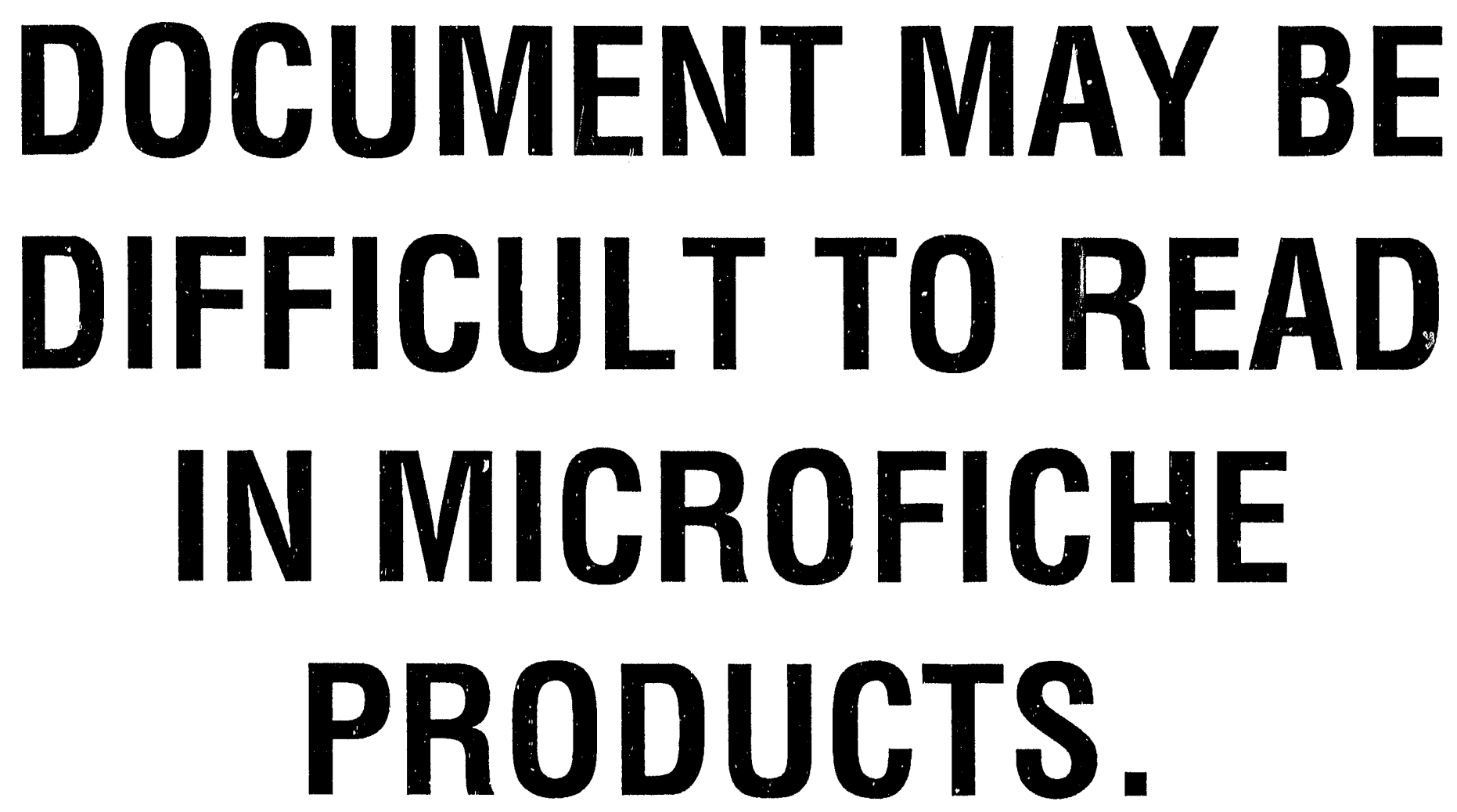


\section{LA-UR $Y U U-3908$}

AUthor(S) Alex H. Lumpkin, Bruce E. Carlsten, and Renee B. Feldman

SUBmitted to 12th FEL Proceedings, Secretariat FEL '90, Ecole Polytechnique, Laboratoire de Physique des Mileau Ionises, 31128 Palaiseau, France

\section{DISCLAIMER}

This report was prepared as an account of work sponsored by an agency of the United States Government. Neither the United States Government nor any agency thereof, nor any of their employees, makes any warranty, express or implied, or assumes any legal liability or responsibility for the accuracy, completeness, or usefulness of any information, apparatus, product, or process disclosed, or represents that its use would not infringe privately owned rights. Reference herein to any specific co,nmercial product, process, or service by trade name, trademark, manufacturer, or otherwise does not necessarily constitute or imply its endorsement, recommendation, or favoring by the United States Government or any agency thereof. The views and opinions of authors expressed herein do not necessarily state or refiect those of the United States Government or any agency thereof.

By acceptance of in:s article the publishet recognizes that the US Government retains a nonexclusive royally. flee license to pubilsh or teproduce ine published $10 \mathrm{~m}$ of inis contribution or 10 allow olners 10 do so tor US Government puiposes

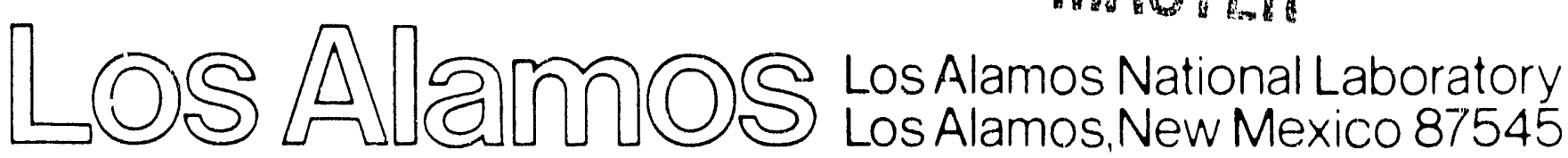




\title{
FIRST MEASUREMENTS OF ELECTRON-BEAM TRANSIT TIMES AND MICROPULSE ELONGATION IN A PHOTOELECTRIC INJECTOR AT THE HIGH-BRIGHTNESS ACCELERATOR FEL (HIBAF)*
}

\author{
Alex H. Lumpkin, Bruce E. Caristen, and Renee B. Feldman \\ Los Alamos National Laboratory \\ Los Alamos, NM 87545 USA
}

\begin{abstract}
Key aspects of the dynamics of a photoelectric injector (PEI) on the Los Alamos High-Brightness Accelerator FEL (HIBAF) facility have been investigated using a synchroscan streak camera. By phase-locking the streak camera sweep to the reference $108.3 \mathrm{MHz}$ if signal, the variations of micropulse temporal elongations (30 to $80 \%$ over the drive-laser pulse length) and of transit times ( $25 \mathrm{ps}$ for a $16^{\circ}$-phase change) were observed for the first time. These results were in good agreement with PARMELA simulations.
\end{abstract}

\section{INTRODUCTION}

The characteristics of the electron beam from a photoelectric injector (PEI) depend critically on the first accelerating cavity. We have investigated the dynamics of the PEl-generated beams on the Los Alamos High-Brightness Accelerator FEL (HIBAF) Facility using a synchroscan streak camera. Because the electron-beam micropulse elongation depends on the balancing of space-charge effects by the if field gradients present when the electrons are released from the photocathode, drive-laser phase is a critical parameter. Similarly, the transit time of the electrons through the first cell also depends on the accelerating fields present at their release, and thus the time it takes to

*Work supported and funded by the U.S. Department of Defense, Army Strategic Defense Command, under the auspices of the U.S. Department of Energy. 
reach relativistic velocities. These dynamic; aspects can serve as important tests of the modeling of the PEI.

Because designers prohibited instrument diagnostics in the accelerator tank, we have utilized the fact that these initial first cell dependencies are preserved in the accelerations up to $17 \mathrm{MeV}$. By phase-locking the streak camera sweep to the reference 108.3 $\mathrm{MHz}$ if signal the variation of elongation and transit time with respect to the drivelaser injection phase were measured. Both the path lengths for the drive-laser signal and the electron-beam signal (Cherenkov light) were adjusted in such a way that they appeared in the same streak sweep. Experimental results were in good agreement with PARMELA simulations as discussed in Section III.

\section{EXPERIMENTAL CONSIDERATIONS}

The HIBAF facility is described in more detail elsewhere in these proceedings [1], but in our initial test configuration there was only the photoinjector (see Fig. 1) tank and a second accelerating tank. The ND:YLF laser oscillator was mode locked to $54.1 \mathrm{MHz}$, pulse compressed, its wavelength doubled in frequericy in a KTP crystal, and pulse selected to provide a few microjoules per micropulse at $21.6 \mathrm{MHz}(1 / 60$ th of the fundamental $1300 \mathrm{MHz}$ if frequency). This drive-laser beam, after mode shape preparation and transport, irradiated a $\mathrm{CsK}_{2} \mathrm{Sb}$ photocathode located in the first accelerator cell. Basically no beam line diagnostics were allowed until after accelerator $\mathrm{B}$. Energies at that point were 15-17 MeV.

Figure 2 shows a schematic of the beam line diagnostics that are addressed also in reference [2]. In these experiments, however, we relied principally on the aluminized fused silica screen \#3, 7-meters c'ownstream of the photocathode. The screen was 
oriented at $45^{\circ}$ to the beam direction so that the Cherenkov light exited almost normal to the screen surface but through an exit port at $45^{\circ}$ to the beam line. The streak camera was located a few meters from the beam line. Transport optics were used to place the image on the entrance slit of the streak camera. Additionally, a fraction of the drive-laser beam was transported to the entrance slit along a path that approximated that of the electron beam plus Cherenkov light path.

A Hamamatsu C1587 streak camera with the synchroscan plugin phase locked to 108.3 MHz was used to detect the two signials. With the optical paths adjusted, both the e-beam and laser beam micropulse were observed in the same sweep of the camera. The system could track single micropulses or the synchronous sum of hundreds of pulses. A NARDA place shifter in the drive laser if side and in the line to the streak camera allowed tracking of the relative if phase changes (Fig. 3).

\section{RESULTS AND COMPARISON TO SIMULATIONS}

The initial experiments were performed in January 1990. Figure 4 shows two streak images of the drive-laser micropulse and the electron beam pulses at two different drive laser phases. An approximately $30^{\circ}$ (60 ps) phase change between the upper and lower figures shows a narrowing of both micropulse length and the change in separation between the micropulses on the time axis. This latter effect is attributed to the change in transit times through the first cell.

A series of such images was taken as a function of the phase shifter on the if to the drive laser. The full-width at half-maximum intensity (FWHM) values and peak position values for both e-beam and drive-laser micropulses were tracked. Figure 5 shows the measured micropulse length variation in picoseconds versus phase. The 
drive-laser micropulse length was monitored through an autocorrelator on the $1.05 \mu \mathrm{m}$ radiation as well as in the doubled frequency via the streak camera (FWHM $=11 \pm 2 p s$ ). The variation of e-beam micropulse of 30 to $80 \%$ is indicated. The solid curve shows a curve calculated from the PARMELA description of the injector was in good agreement with experiment. In Fig. 6, the transit-time phase dependence is shown. One of the interesting features is at higher fields in the cell (larger phase \#), the transit time effect saturates so arrival times all fall in a 25 ps window.

Within the course of these streak camera experiments, we turned off the drive laser to establish backgrounds. We actually were able to synchronously integrate the field emission electrons from the photocathode. In Fig. 7, beam transport was not optimized, but the two doublets result from electrons generated at $1300 \mathrm{MHz}$ arriving phase locked to both sides of the sinusoidal streak sweep. A 42-ps variation of the NARDA phase shifter in line to the streak unit if causes the motion of the two doublets in opposite "time" directions. Figures 8a-d, then show the strong, nonlinear dependence of the beam images (viewed via OTR signals) versus accelerator $A$ fields. A factor of five decrease in electrons for only a $20 \%$ decrease in field at the photocathode was observed. The $\mathrm{f}$ tank probe reading of $300 \mathrm{mV}$ corresponds to about $26 \mathrm{MV} / \mathrm{m}$ at the photocathode. Further experiments and results on these field emission electrons will be reported elsewhere.

\section{SUMMARY}

In summary, by phase-locking the synchroscan streak camera sweep to the reference $108.3 \mathrm{MHz}$ if signal, the variations of e-beam micropulse elongation and transit time with drive-laser injection phase were measured. These two phenomena have been 
observed for the first time in a PEI, and their phase dependencies have been shown to agree with PARMELA simulations. This understanding can also be applied to the unexpected field emission electron source. These techniques can be used then in optimization of the PEI performances.

\section{ACKNOWLEDGMENTS}

The authors acknowledge the contributions of Los Alamos personnel Mark Wilke, Scott Apgar, Steve Bender, Nathan Okamoto, and Mike Feind on the optical path length setups and Don Feldman, Joel Johnson, Bill Stein, Jim Early, and Jerry Barton on operations of the HIBAF facility.

\section{FIGURE CAPTIONS}

Fig. 1. Schematic of photoinjector accelerator.

Fig. 2. Schematic of HIBAF beamline diagnostics.

Fig. 3. Schematic of Dual Sweep Streak Technique.

Fig. 4. Simultaneous synchroscan streak images of e-beam (Cherenkov converter) and drive laser.

Fig. 5. Micropulse length variation with drive.

Fig. 6. Transit time effects vs. drive laser phaser in the photoinjector.

Fig. 7. Synchroscan streak images of field emission electrons vs. input RF phase shifts.

Fig. 8. Field emission electrons imaged at $17 \mathrm{MeV}$ versus accelerator $\mathrm{A}$ field with probe readings in $\mathrm{mV}:$ a) 300, b) 280, c) 260 , and d) 240 . 


\section{REFERENCES}

1. D. W. Feldman, et al., "Performance of the Los Alamos HIBAF Accelerator at 17 MeV," Proceedings of the 12t? International Free-Electron Laser Conference, Paris, France, Sepumber 16-21, 1990.

2. A. H. Lumpkin, et al., "Initial Observations of High-Charge, Low-Emittance Electron Beam at HIBAF," These Proceedings. 


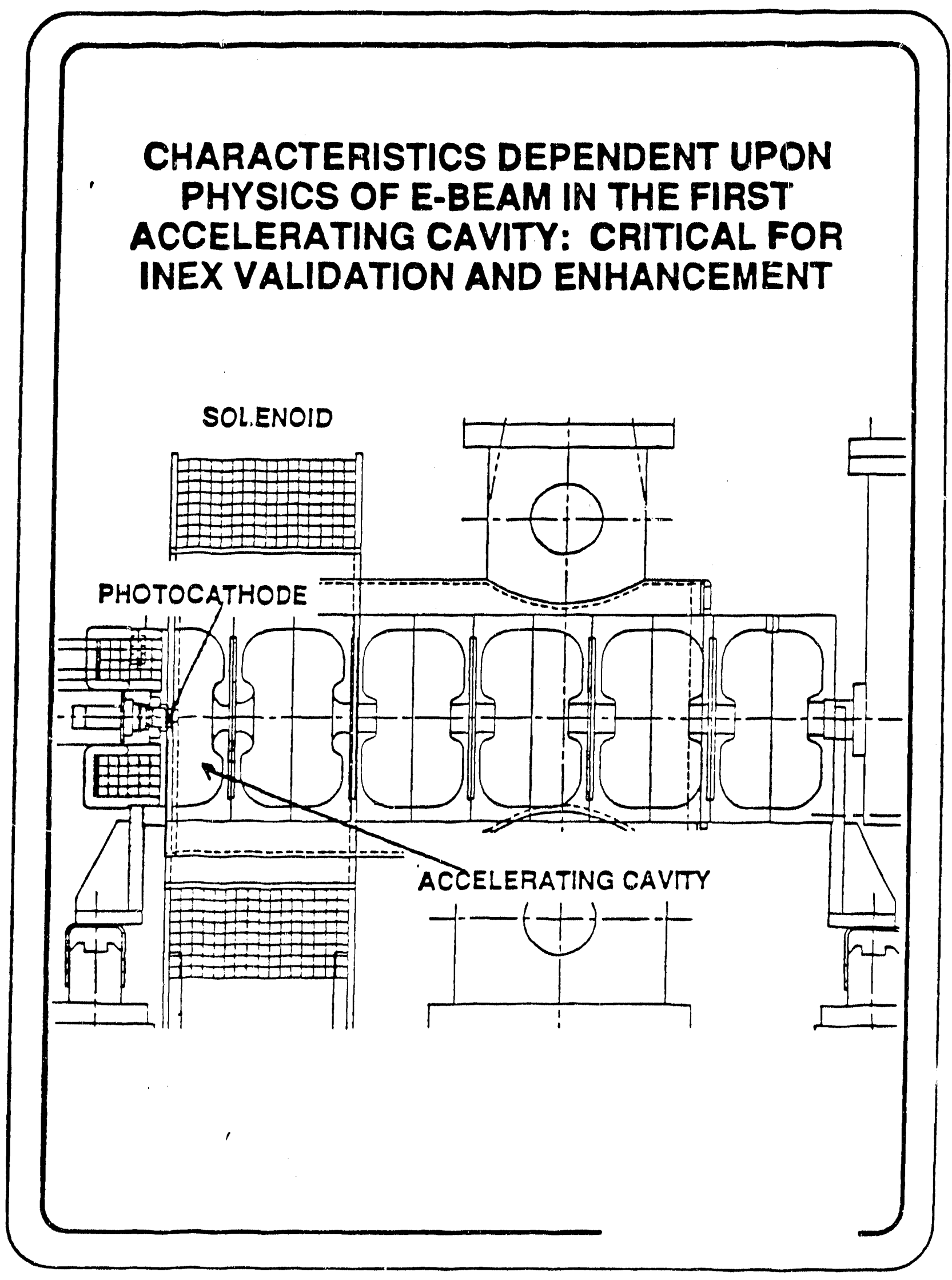




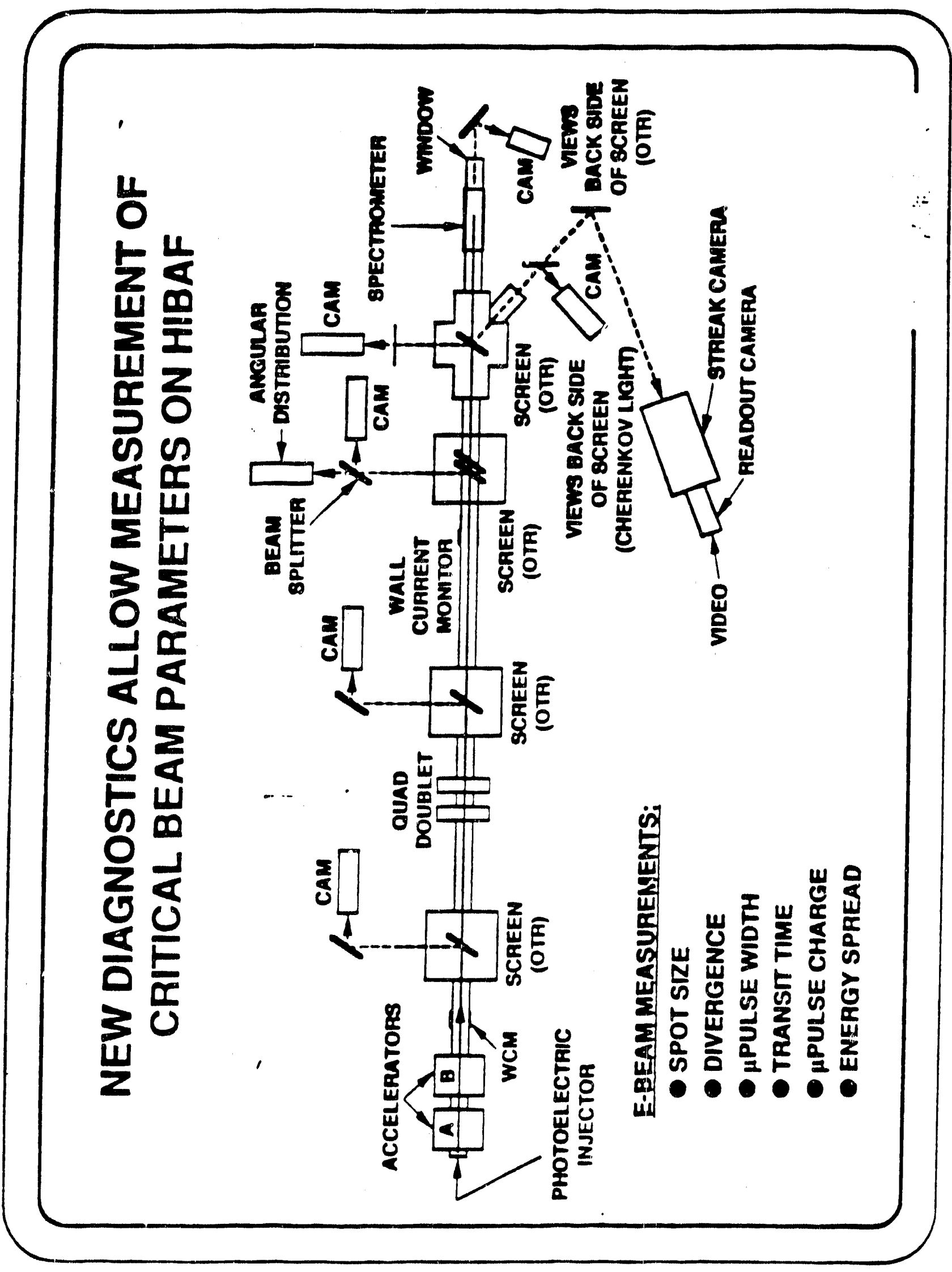




\section{SCHEMATIC OF DUAL SWEEP STREAK TECHNIQUE}

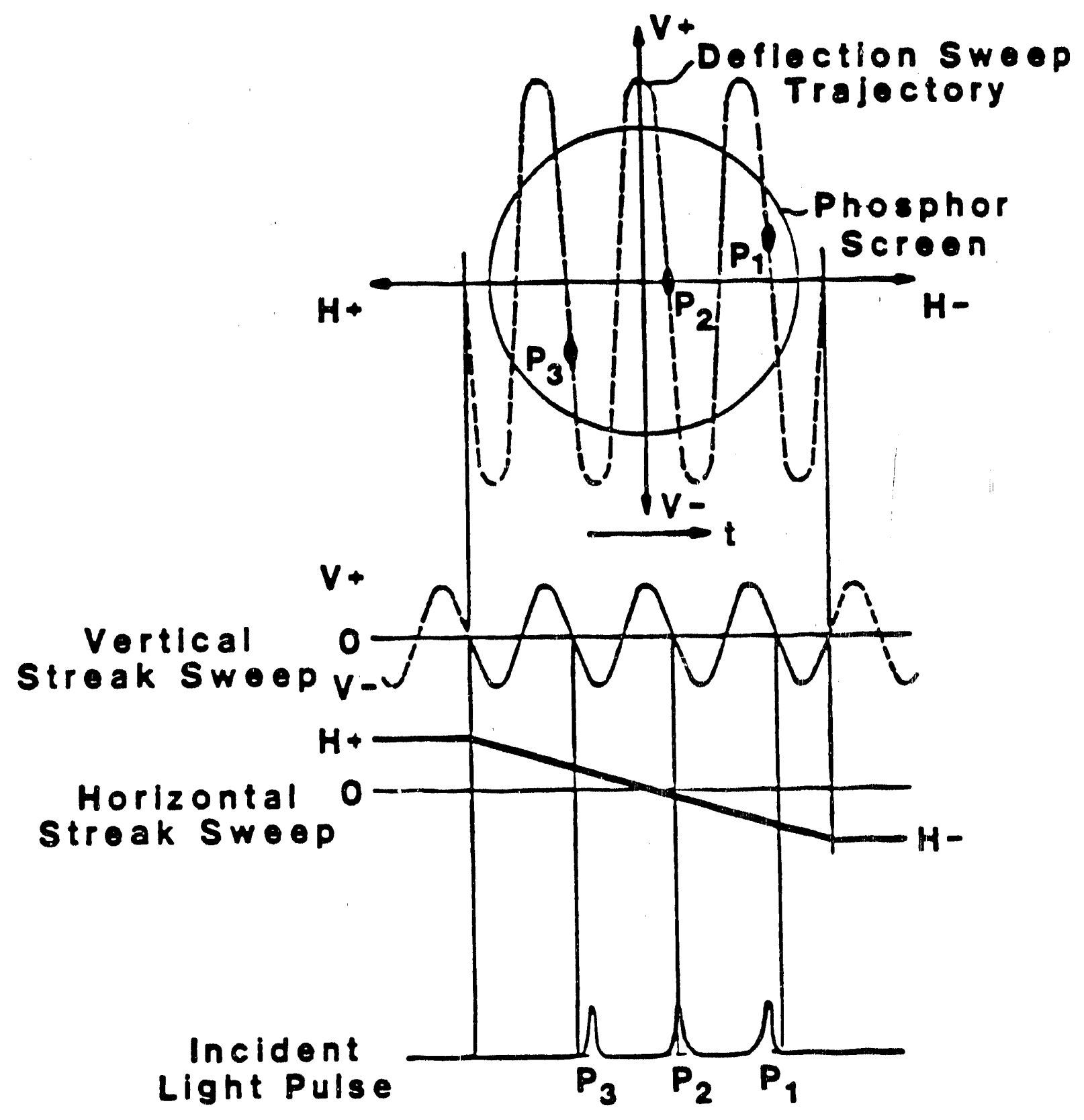




\section{SIMULTANEOUS SYNCHROSCAN STREAK OF E-BEAM/DRIVE LASFR (DL) \\ (D. L. PHASE EFFECT)}

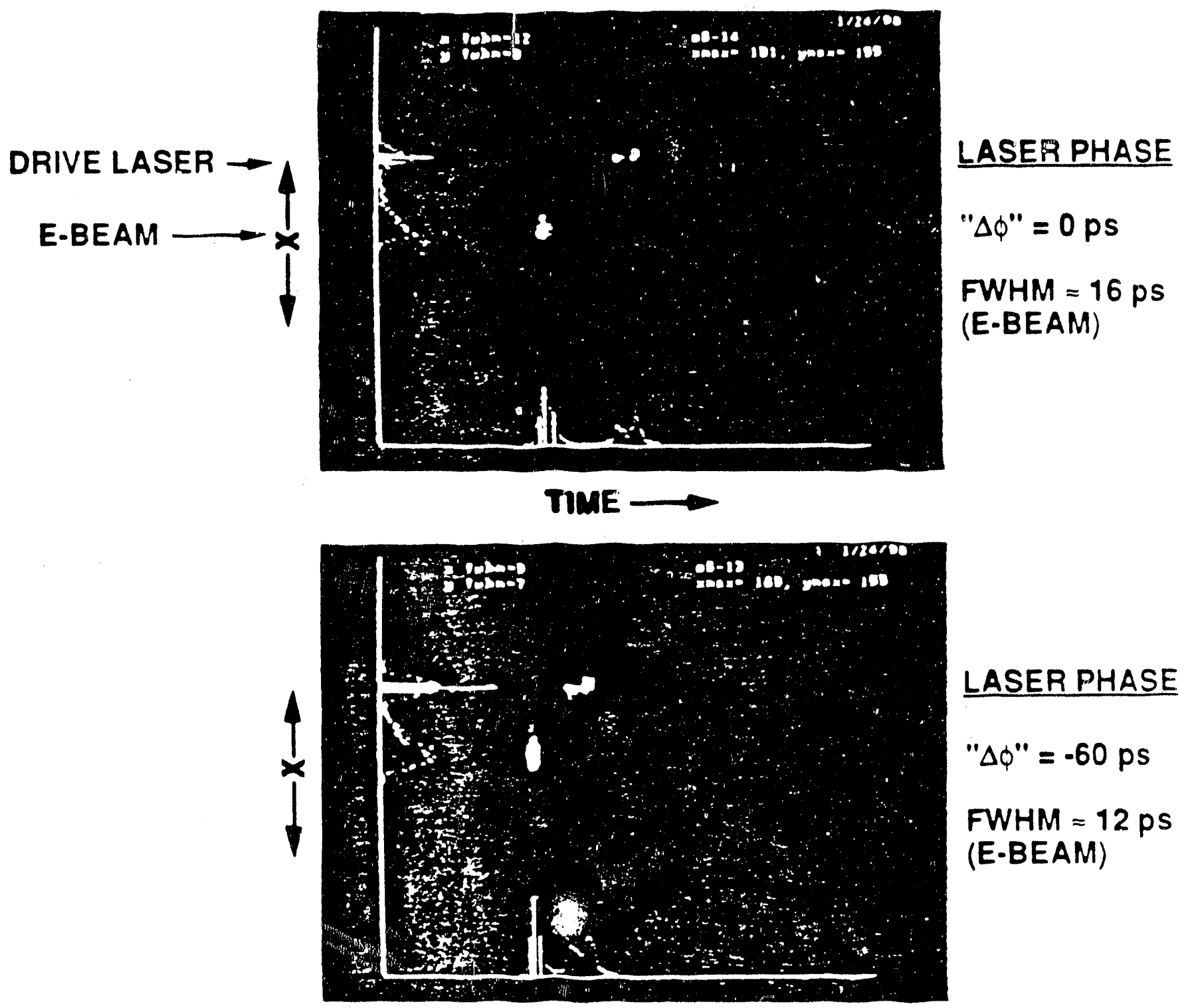

TIME

AUTO CORR.

- 13 ps 


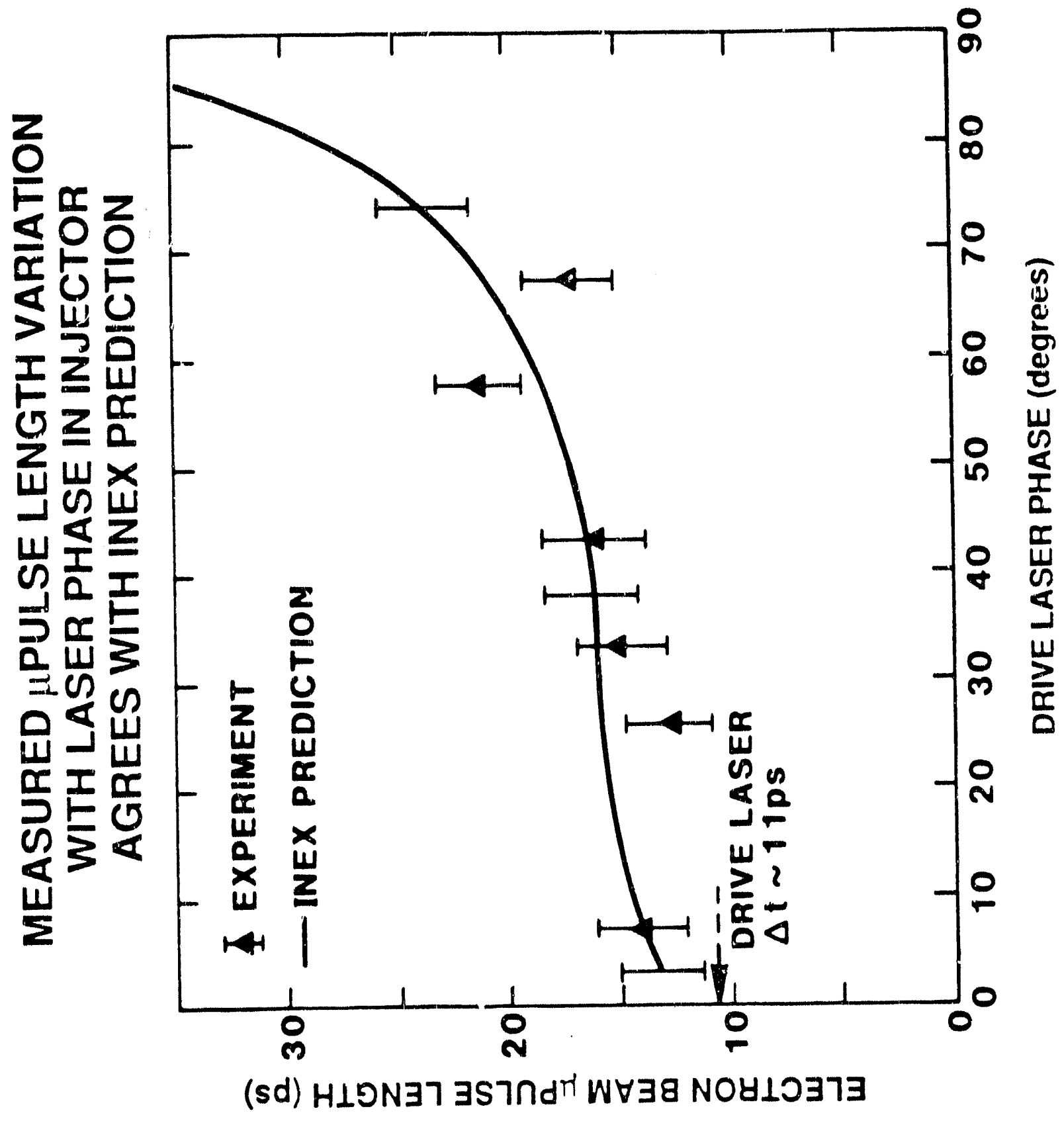




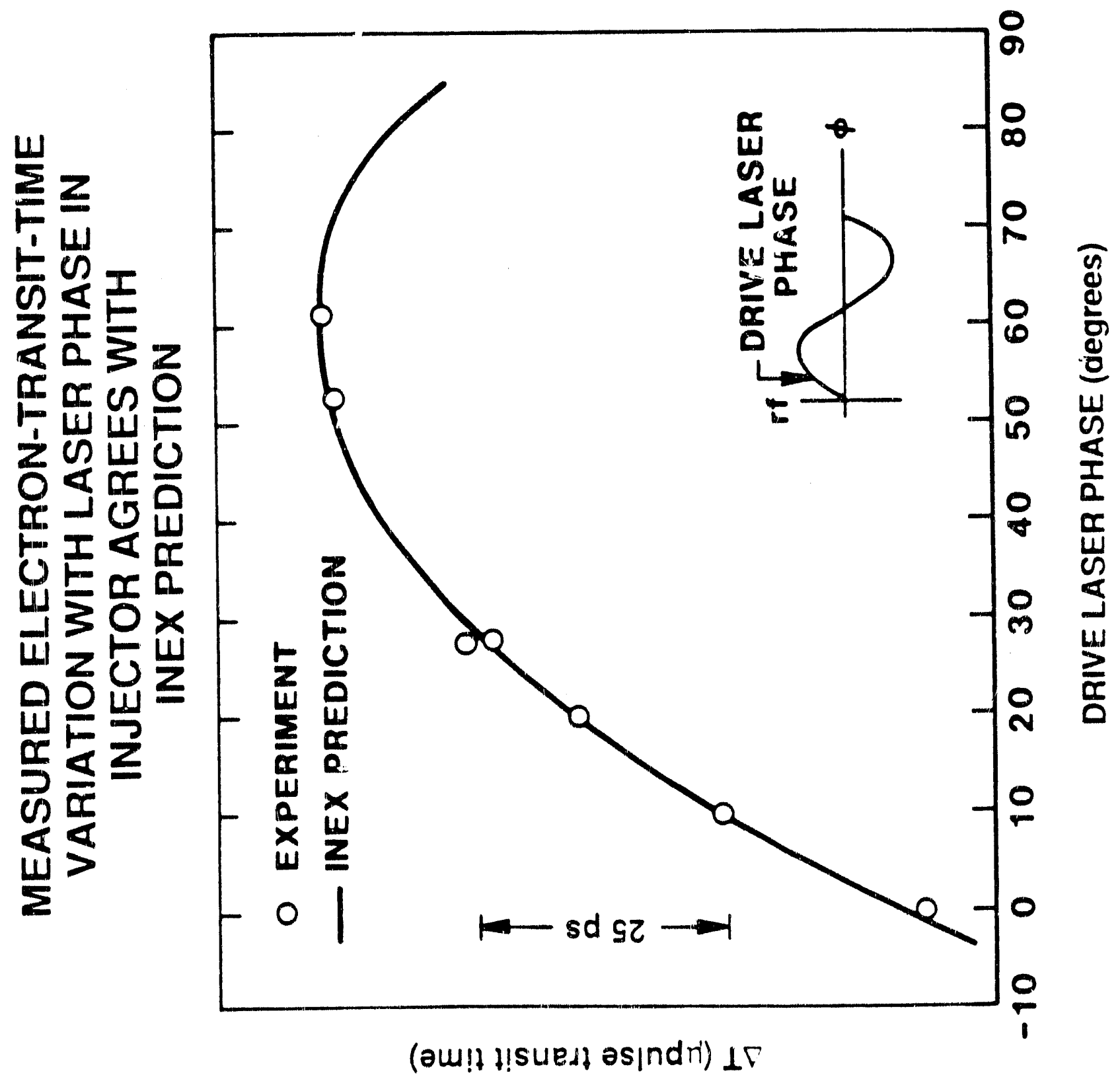




\section{SYNCHROSCAN STREAK IMAGES SHOW PHASE EFFECTS ON FIELD EMISSION ELECTRONS

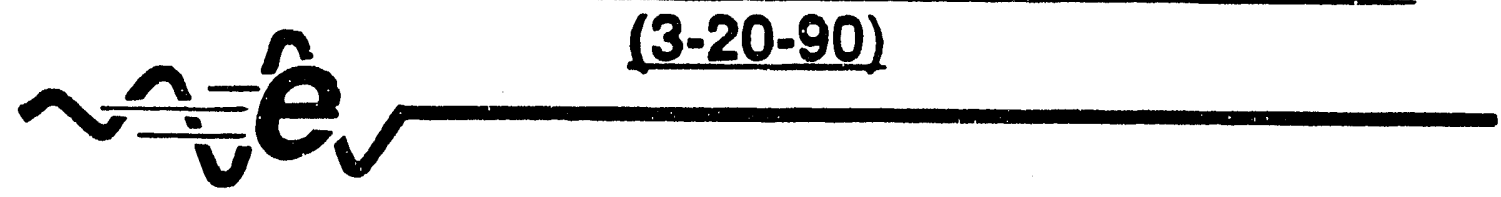

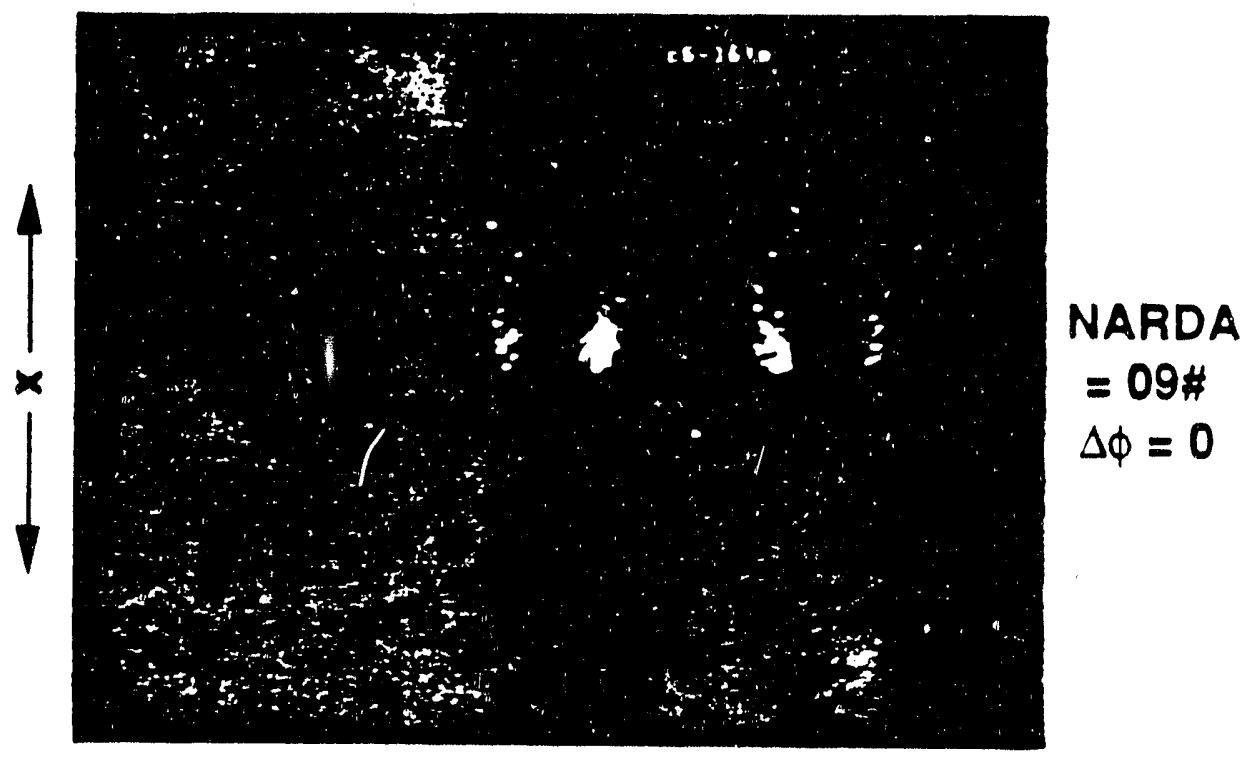

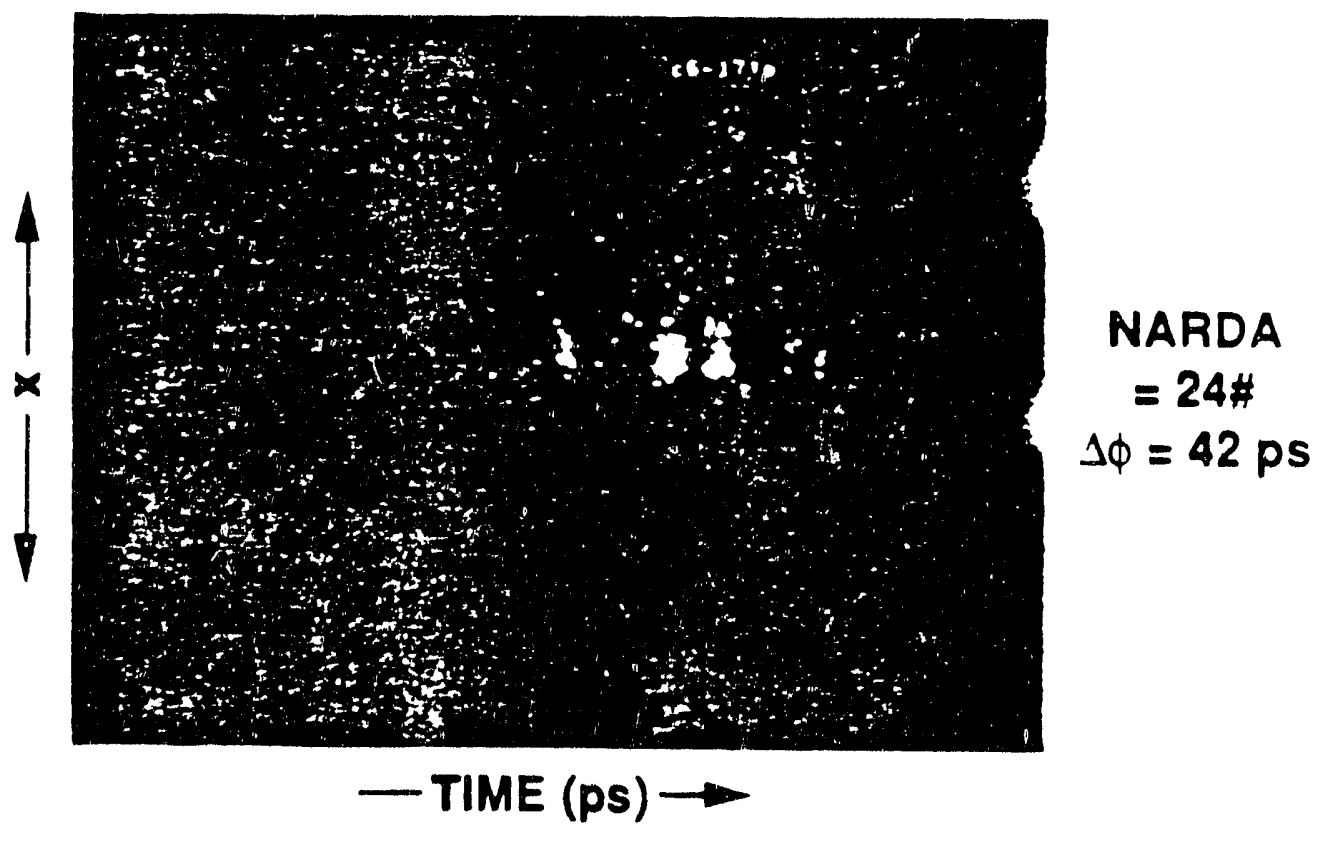




\section{FIELD EMISSION ELECTRONS VARY WITH TANK-A FIELDS (3-20-90)}

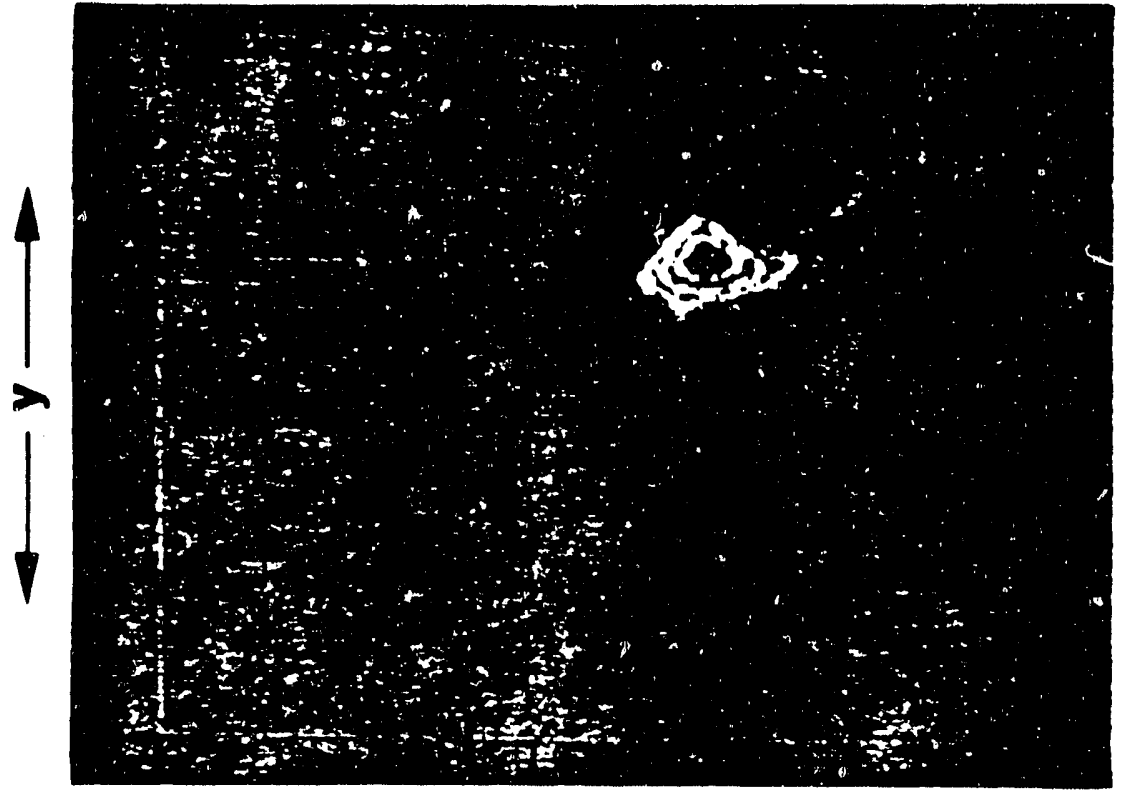

Accel. A: Ampl. $=300 \mathrm{mV}$ $I_{p k}=1.0$
Box Average
of x-Profile

a)

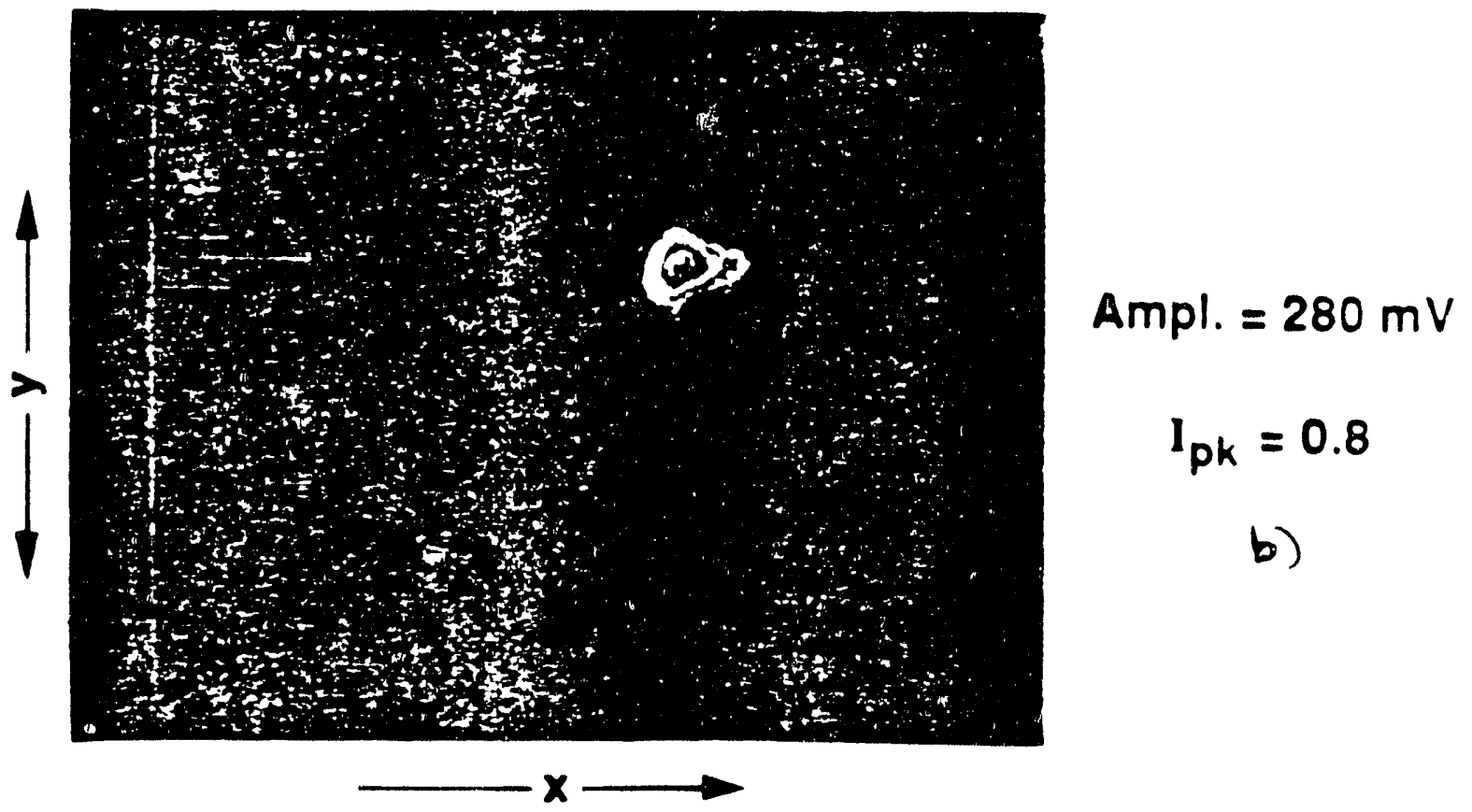



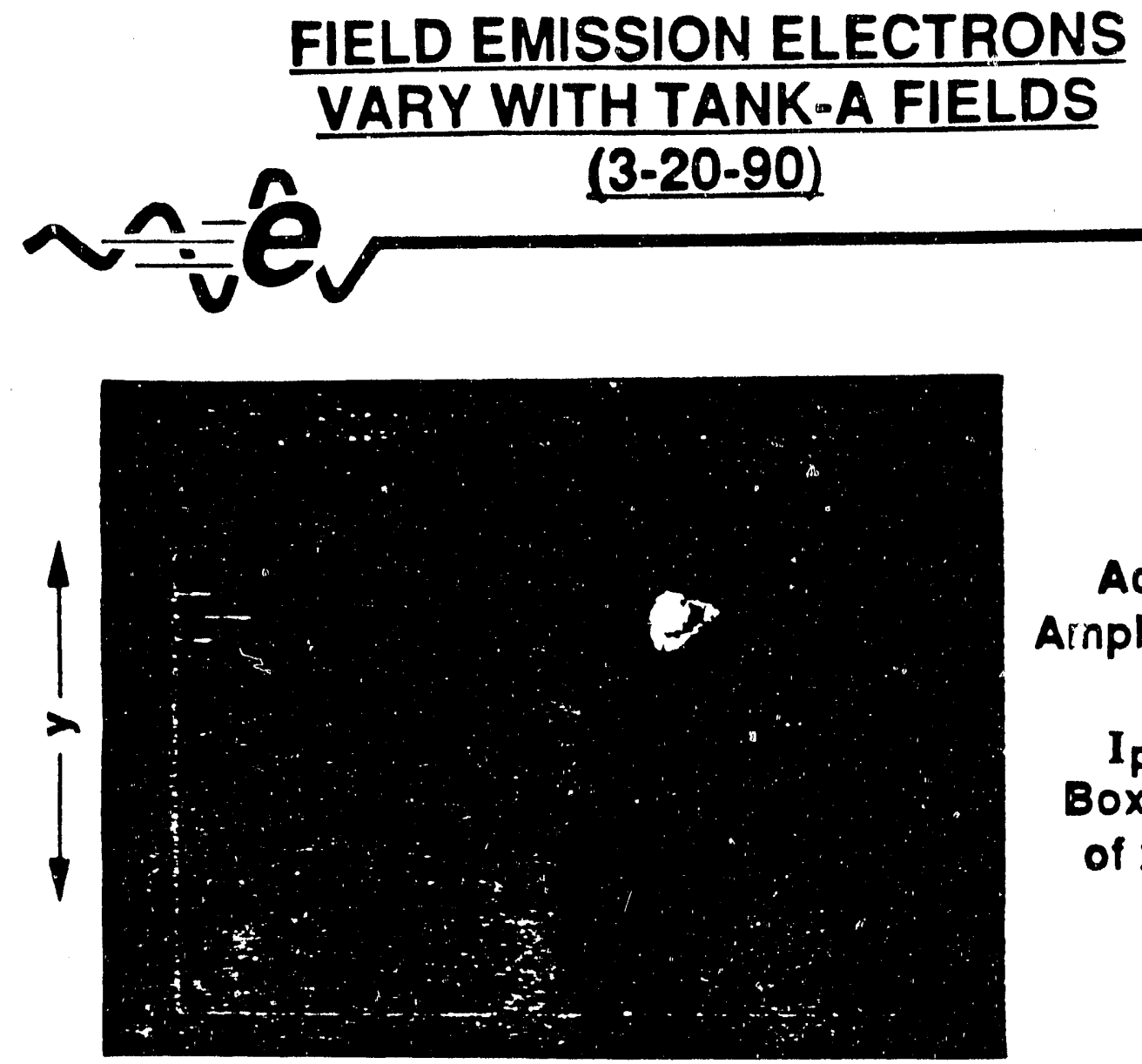

Accel. A:

Ainpl. $=260 \mathrm{mV}$

$$
I_{p k}=0.4
$$

Box Average

of $x$-Profile

C)

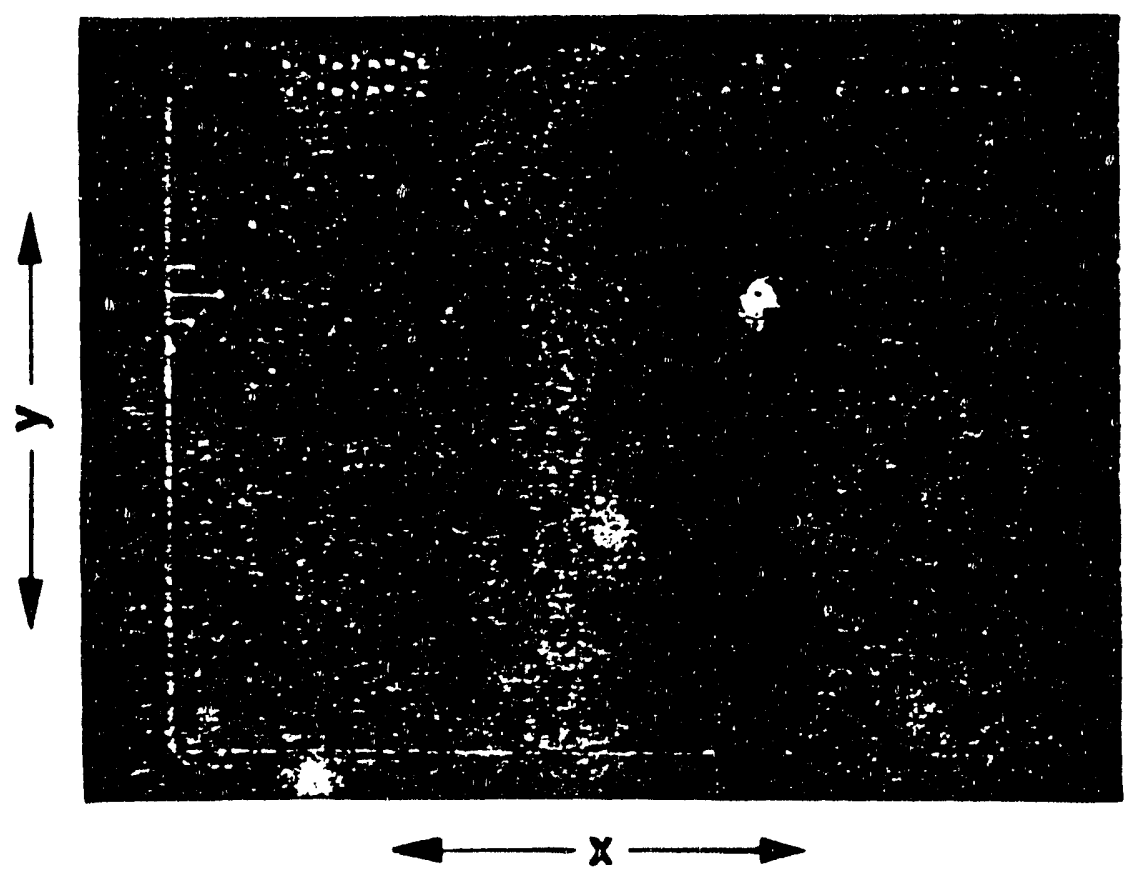

$$
\begin{gathered}
\text { Ampl. }=240 \mathrm{mV} \\
\frac{A_{4}}{A_{1}}=0.80 \\
I_{\text {pk }} .0 .2 \\
\text { d) }
\end{gathered}
$$



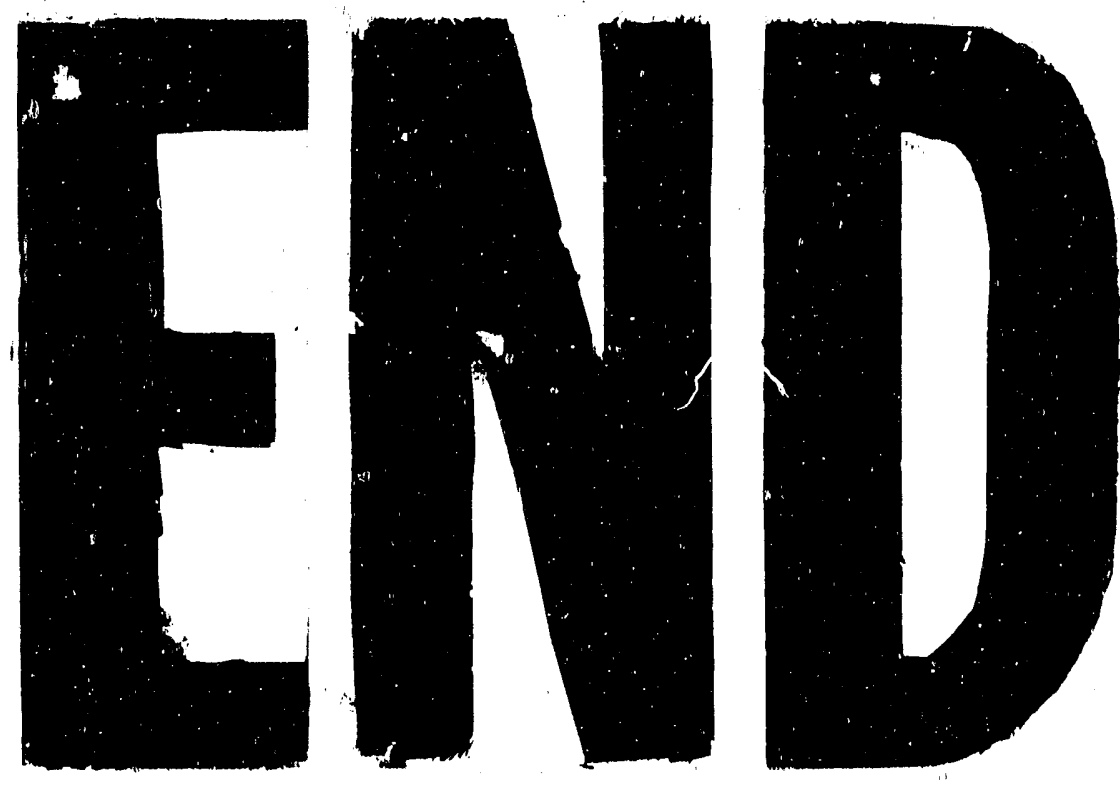

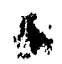
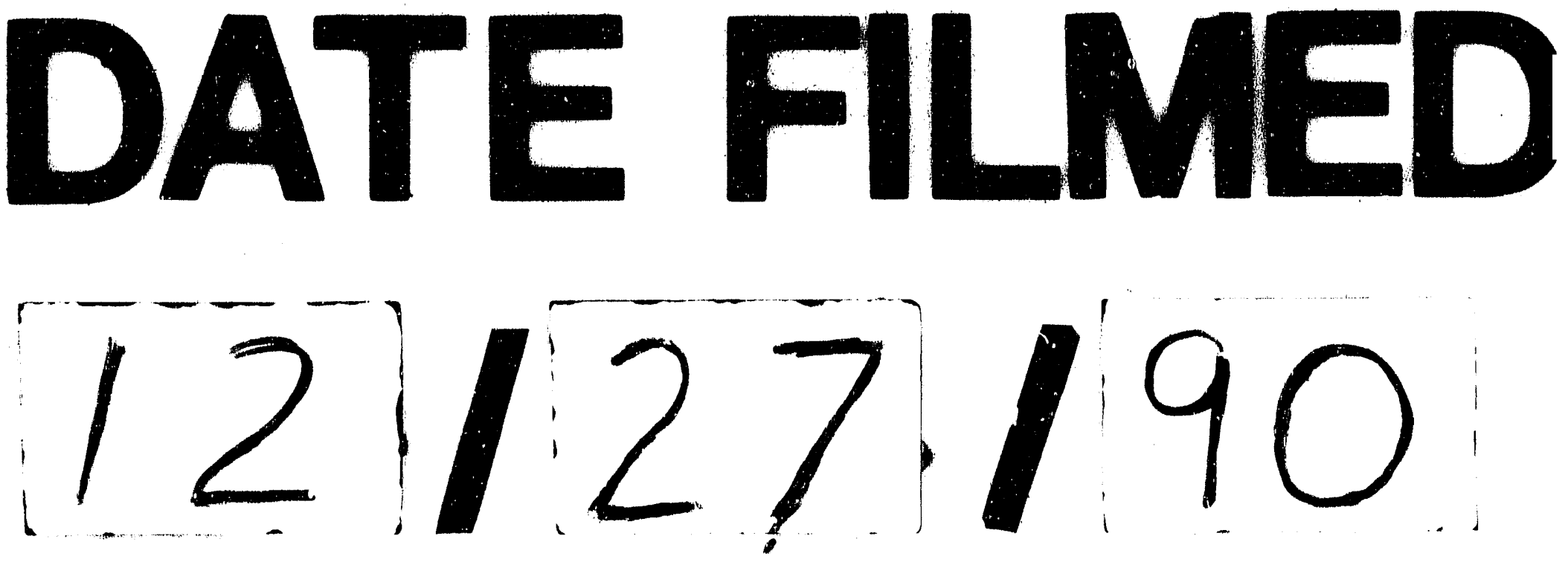
